\title{
Diferenciais da distância geográfica na interação universidade-empresa no Brasil: um foco sobre as características dos agentes e das interações
}

Geographical distance differentials in university-firm interaction in Brazil: a focus on the characteristics of agents and interactions

\author{
Thiago Caliari \\ Instituto Tecnológico da Aeronáutica \\ Márcia Siqueira Rapini \\ Universidade Federal de Minas Gerais
}

\begin{abstract}
The article aims to analyze the determinants of the geographical distance of universityindustry interactions in Brazil. By controlling for variables already studied and identified as relevant for explaining the geographical distance of interactions, the results indicate the existence of differences in the pattern of behavior (i) for research groups located in different types of institutions and belonging to distinct scientific areas, (ii) for firms classified by technological appropriateness and capacity and (iii) for the type and funding of interactions.
\end{abstract}

\section{Keywords}

university-industry interaction; geographical proximity; research groups.

JEL Codes C10; O3; O54.

\section{Resumo}

$O$ artigo analisa os determinantes da distância geográfica das interações universidade-empresa no Brasil, utilizando-se dos microdados do Censo 2008 do Diretório dos Grupos de Pesquisa do CNPq. Controlando para variáveis já estudadas e apontadas como relevante para a explicação da distância geográfica nas interações, os resultados apontam a existência de diferenças no padrão de comportamento (i) dos grupos de pesquisa situados em distintos tipos de instituição e pertencentes a distintas grandes áreas, (ii) das empresas classificadas por capacitação e apropriabilidade tecnológica e (iii) dos tipos de relacionamento e financiamento estabelecidos.

\section{Palavras-chave}

interação universidade-empresa; proximidade geográfica; grupos de pesquisa do $\mathrm{CNPq}$.

Códigos JEL C10; O3; O54. 


\section{Introdução}

O conhecimento e a informação vêm desempenhando um papel estratégico no desenvolvimento econômico e no crescimento das empresas (Lastres; Albagli, 1999). O conhecimento é um insumo importante no processo inovativo, sendo construído a partir da combinação de conhecimento tácito e codificado, podendo ser interno ou externo à empresa. Porém, para que tais firmas consigam identificar, assimilar e utilizar o conhecimento gerado em outras instituições, é necessário que as mesmas desenvolvam uma capacidade interna de absorção (Cohen et al., 2002).

O papel da pesquisa acadêmica no processo inovativo é um processo dinâmico, sendo mais ou menos intenso em determinadas etapas, além de distinto e específico nos setores da economia. Vários autores realizaram estudos na tentativa de mapear a importância das diversas áreas de conhecimento no processo inovativo (Klevorick et al., 1995; Narin et al., 1997; Mansfield, 1991), bem como a importância da proximidade geográfica para a troca de conhecimento tácito (Jaffe et al., 1993; Schartinger, et al., 2002).

Porém, a literatura também aponta que a proximidade geográfica, apesar de condição necessária, não é suficiente para a existência de interações que levem à transmissão do conhecimento. Outros determinantes devem ser considerados para o entendimento da ocorrência dessas interações.

Este paper analisa os diferentes padrões de distância das interações U-E, considerando variáveis trabalhadas na literatura nacional e internacional, dentre elas as grandes áreas de pesquisa dos grupos, a instituição à qual o grupo está fundado, as empresas classificadas por capacitação tecnológica e os canais de relacionamento estabelecidos nas interações, controlando para demais variáveis já identificadas como relevantes em outros trabalhos da área. O propósito é avançar na compreensão da importância da proximidade geográfica entre os agentes nos relacionamentos interativos frente a demais características, identificando padrões diferenciados que possam fornecer respaldo empírico para políticas públicas de fomento à ciência, tecnologia e inovação. As especificidades regionais da interação universidade-empresa no Brasil ainda que sejam relevantes (Suzigan et al., 2011) não são objeto de análise neste trabalho.

O artigo está organizado em cinco partes, incluindo esta introdução. A segunda parte apresenta revisão da literatura sobre a importância da 
proximidade geográfica na interação universidade-empresa, bem como de outros determinantes. A revisão serve de pano de fundo para a definição do modelo e das variáveis utilizadas. A terceira sessão apresenta a base de dados utilizada, os microdados do Censo 2008 do Diretório dos Grupos de Pesquisa do $\mathrm{CNPq}$, bem como o modelo e as variáveis utilizadas. A quarta parte destaca os resultados da estimação e uma discussão sobre esses resultados comparativamente a demais trabalhos, resguardadas as especificidades nacionais. A quinta parte conclui o trabalho fazendo reflexões sobre o resultado brasileiro e os encontrados na literatura internacional.

\section{A proximidade geográfica é suficiente? Evidências empíricas e características relevantes}

O estudo das vantagens competitivas de uma nação ou região é destacado na tradição de estudos de Sistemas de Inovação (SI) e Sistemas Regionais de Inovação (SRI) (Cooke, 1998; Oinas; Malecki, 1999). Brenner (2001) sintetiza as principais interações passíveis de existência entre os agentes em um sistema regional, com ênfase para a proximidade, que são por ele enumeradas: a) firmas de uma mesma indústria ou indústria relacionada, ou da mesma cadeia produtiva; b) mercado de trabalho; c) mercado de capitais; d) universidades e instituições de pesquisa; e) política. Para que essas interações levem à criação de atividade econômica adicional, é necessária a existência de algum processo acumulativo, em que o incremento de uma variável leva ao aumento de uma ou de outras variáveis exercendo efeito positivo na primeira variável (positive feedback-loops) ${ }^{1}$.

Uma primeira interação, já amplamente discutida na literatura, é a disponibilidade de mão de obra adequada para as firmas. A aparente baixa mobilidade da mão de obra leva a firma a depender do mercado de trabalho local. A teoria da firma baseada em capacidades ou recursos vai um pouco mais além, enfatizando a importância dos recursos humanos na diversificação das firmas e em suas estratégias. Nesses termos, o processo de aprendizado (learning-by-doing e learning-by-using) gera conhecimento tácito interno (Nelson; Winter, 1982). As firmas, portanto, não apenas de-

1 Para Antonelli (2001), os retornos crescentes dos distritos industrias seriam resultantes da dinâmica dos feed-backs positivos, dos esforços comunicativos implementados e do acesso a externalidades locais de conhecimento. 
pendem de mão de obra adequada, como também criam capital humano não transmissível.

Uma segunda interação é a das firmas com universidades e instituições de pesquisa. As universidades contribuem de duas formas principais: com a formação de recursos humanos que serão empregados pelas empresas e na realização de pesquisas. Ademais, as pesquisas acadêmicas podem contribuir para a solução de problemas gerados nas firmas, para a proposição de novos projetos, para o desenvolvimento de novas técnicas, instrumentos e protótipos (Cohen et al., 2002). A transmissão do conhecimento gerado nas universidades para as firmas pode ocorrer de diversas formas, por exemplo, via publicações científicas, contratos de $\mathrm{P} \& \mathrm{D}$ ou cooperação formal/informal na realização de atividades de $\mathrm{P} \& \mathrm{D}$, treinamento, consultoria, transferência de tecnologia, entre outras. A transmissão do conhecimento científico tácito, em particular, pode ser favorecida pela proximidade geográfica entre os agentes.

As universidades são uma importante fonte externa de conhecimento para a criação de novo conhecimento nas empresas. Alguns estudos buscaram mensurar a dimensão da contribuição do componente tácito do conhecimento científico para o processo inovativo. Por estar embutido no indivíduo, sua forma de transmissão (i.e. a troca de conhecimento) se dá principalmente via mobilidade pessoal e contatos face-a-face. Além do mais, a comunicação informal leva à confiança mútua que aumenta a propensão em cooperar na realização de $\mathrm{P} \& \mathrm{D}$. Esse fenômeno tende, portanto, a ser localizado em termos geográficos e linguísticos (Pavitt, 1998).

Em suma, é fato definido que a proximidade geográfica tem um importante papel no delineamento das interações universidade-empresa. Aspectos estruturais, comportamentais, geográficos e relacionados a políticas públicas são amplamente difundidos como determinantes das possibilidades de interação no contexto locacional (De Fuentes; Dutrénit, 2014). Nesse sentido, uma gama de estudos verifica essa validade frente a demais características dos agentes e dos relacionamentos.

Jaffe et al. (1993) analisaram os spillovers do conhecimento universitário para a atividade inovativa na economia norte americana nos anos de 1975 e 1980, valendo-se das citações de origem acadêmica nas patentes de invenção ${ }^{2}$. Encontraram resultados significativos, principalmente para 2 "Despite the invisibility of knowledge spillovers, they do leave paper trial in the form of citation" (Jaffe et al., 1993, p. 595). 
o ano de 1980, indicando que os spillovers do conhecimento acadêmicos são concentrados geograficamente. Em um estudo anterior, Jaffe (1989) havia encontrado significativa contribuição da pesquisa universitária nas indústrias farmacêuticas, de tecnologia médica e nuclear, de eletrônicos e de instrumentos ópticos, sinalizando que os spillovers seriam limitados a áreas específicas e não à pesquisa universitária como um todo. Além do mais, efeitos de causalidade significativos emergiram da pesquisa acadêmica para o $\mathrm{P} \& \mathrm{D}$ industrial.

Acts et al. (1994) realizaram o mesmo tipo de análise de Jaffe (1989) utilizando, porém, uma medida de inovatividade ${ }^{3}$ ao invés de patentes concedidas. Concluíram que os efeitos dos spillovers das universidades e da proximidade geográfica seriam aparentemente maiores em inovações do que em invenções patenteadas, e que as firmas menores tendem a ser mais inovativas. Em relação à importância do spillover acadêmico nos gastos em $\mathrm{P} \& \mathrm{D}$ industrial, resultados significativos foram encontrados no setor de eletrônicos.

Schartinger et al. (2002) encontraram, em estudo específico para a Áustria, que além da proximidade geográfica ser importante para potenciais colaborações entre universidade e firmas, a troca de conhecimento se dá por vários "canais", de forma que a ênfase na colaboração direta subestima a importância das outras formas de interação. Nas indústrias intensivas em $\mathrm{P} \& \mathrm{D}$ e na ciência técnica, a cooperação direta tende a ser mais intensiva, ao passo que no setor de serviços e nas ciências sociais e econômicas as interações mais frequentes são mobilidade pessoal e treinamento. McKelvey et al. (2003), em um estudo da indústria biofarmacêutica na Suécia, encontraram indícios de que as publicações científicas das firmas pequenas tendiam a ser em coautoria com universidades próximas, sinalizando que essas firmas, geralmente criadas por cientistas, continuavam interligadas com a universidade de origem.

Mansfield e Lee (1996) encontraram pouca relevância para a proximidade geográfica quando o objetivo era o acesso a pesquisas de caráter mais básico, sendo preponderante a qualidade do corpo docente. Laursen et al. (2011) apontam resultados congruentes com esse. Por outro lado, Mansfield e Lee (1996) destacam que para as atividades de P\&D aplicar a proximidade geográfica das instituições de pesquisa seria fundamental, visto a 3 Número de atividades inovativas em 1982 contabilizadas pela US Small Business Administration que foram introduzidas do mercado. 
importância de interações pessoais e do trabalho em conjunto. Em trabalho mais recente de D'Este e Iammarino (2010), esse resultado é corroborado para uma base de dados do Reino Unido, cobrindo um período de interações entre 1999-2003, considerando interações de parcerias para P\&D.

Em relação ao tamanho das firmas, Beise e Stahl (1999) percebem que na Alemanha a transferência de conhecimento das universidades e instituições públicas era realizada de forma mais efetiva para grandes firmas, independente da proximidade geográfica. Por outro lado, efeitos de spillovers significativos emergiram das escolas politécnicas para as firmas pequenas, o que estaria sinalizando que as mesmas estariam compensando a ausência de conhecimento interno e de atividade de $\mathrm{P} \& \mathrm{D}$ engajando-se em parcerias com o setor público.

Além da proximidade geográfica, Varga (1997) adiciona a existência de determinada concentração espacial de atividades econômicas como essencial para uma significativa transferência de tecnologia da universidade. Certo nível de massa critica é necessário na aglomeração, a fim de que efeitos econômicos substanciais dos gastos da pesquisa acadêmica possam surgir. Nesse sentido, para o autor, nas firmas de alta tecnologia, os maiores impactos das universidades são nas atividades não rotineiras.

Lemarié, Mangematin, e Torre (2001) mostram, em estudo específico para as empresas de biotecnologia da França, que a localização é importante para a interação, mas tende a ter efeitos dissipados com o aumento de escala e escopo das firmas industriais. Os resultados de Monjon e Waelbroeck (2003) apontam para a mesma direção, mas ao invés da classificação por escala das firmas, apontam para a capacitação tecnológica das mesmas. Segundo os autores, firmas envolvidas em atividades de inovação incremental tendem a ter maiores benefícios na proximidade geográfica com universidades. Firmas com alta taxa de inovação, ao contrário, tendem a derivar maiores benefícios de pesquisas com universidades estrangeiras de excelência acadêmica. Laursen et al. (2011) analisam a importância da proximidade e concluem que ela é importante especialmente para firmas com capacidade de absorção prévia.

Mariani (2004) encontra resultados que contrastam com os obtidos em Lemarié, Mangematin, e Torre (2001) para a indústria de biotecnologia. Com uma base de dados de firmas europeias de química tradicional e de biotecnologia, a autora encontra relevância da localização na geração de spillovers de conhecimento para a inovação das firmas de biotecnologia, 
e relevância dos determinantes internos de $\mathrm{P} \& \mathrm{D}$ e escala industrial das firmas do setor de química.

Arza e Vasquez (2010) apontam que interações mais próximas tendem a possuir um viés pró-mercado mais forte. Empresas e universidades que se encontram em uma mesma região tendem a ter correlações mais forte entre papers publicados e citações em patentes. Brostrom (2010), de modo similar, aponta que a proximidade locacional é mais importante nas interações com objetivo de projetos de $\mathrm{P} \& \mathrm{D}$ de curto prazo voltados para o mercado; em projetos de longo prazo, a proximidade geográfica torna-se um fator menos importante.

No contexto brasileiro, alguns estudos apontam a relevância do ambiente nos padrões de interação U-E. Santos (2009) analisa o sistema regional de inovação mineral-metalúrgico de Minas Gerais, com ênfase no pioneirismo da Escola de Minas de Ouro Preto e na atuação do Departamento de Engenharia Metalúrgica da Universidade Federal de Minas Gerais junto ao setor produtivo. Bittencourt e Rapini (2009) e Bittencourt et al. (2012) apontam a relevância da localização das universidades próximas a aglomerações produtivas nos setores específicos de metal-mecânico e químico-farmacêutico, respectivamente. Maia (2005), em um estudo da interação entre universidades e empresas no polo petroquímico de Salvador, aponta que as empresas da região usualmente recorrem a universidades do Sudeste/Sul brasileiro, pela excelência de conhecimento, em detrimento das universidades mais próximas.

Garcia et al. (2011) investigam o papel da proximidade geográfica em nível amplo, e identificam que uma parcela significativa das interações U-E ocorre no mesmo espaço geográfico. Ainda, encontram a relevância da diversificação da estrutura produtiva local no estímulo às interações. O mesmo resultado é potencializado em Garcia et al. (2014), em que os autores destacam a relevância da qualidade acadêmica e da estrutura da localização da firma para a interação em distintos níveis regionais.

Em suma, os estudos apontam para a relevância da proximidade geográfica na interação universidade-empresa, mas distintas realidades tendem a ter diferentes padrões de relevância nessa consideração. Muitas vezes, as interações ocorrem entre agentes localizados em distâncias consideráveis um do outro. Segundo Breschi e Lissoni (2001), a proximidade geográfica não é uma condição suficiente para a existência de interações que levem à transmissão do conhecimento ou à geração de tecnologia, pois existe uma 
ampla variedade de mecanismos de transmissão de conhecimentos que podem suscitar a interação.

A variedade de apontamentos fornece uma gama de possibilidades e direcionamentos na definição de uma pesquisa que procure proceder com o estudo da relevância regional em interação U-E. Podem-se elencar nos pontos abaixo algumas das principais constatações verificadas na literatura supracitada.

1. Escala / especialização-diversificação econômica da localidade: Varga (1997); Santos (2009); Bittencourt; Rapini (2009) e Bittencourt et al. (2012); Garcia et al. (2011); Garcia et al. (2014).

2. Escala / escopo / capacitação tecnológica e capacidade de absorção das empresas: Beise; Stahl (1999); Harmon et al. (1997); Lemarié; Mangematin; Torre (2001); Mariani (2004); Laursen et al. (2011).

3. Excelência e escala dos centros de pesquisa: Mariani (2004); Mansfield (1995); Maia (2005); Laursen et al. (2011); Garcia et al. (2014).

4. Tipos de pesquisa científica / relacionamento / resultado: Acts et al. (1994); Monjon; Waelbroeck (2003); Arza; Vasquez (2010); Brostrom (2010); De Fuentes; Dutrénit (2014).

5. Áreas científicas de atuação dos grupos de pesquisa e/ou setores industriais de atuação das empresas: Jaffe (1989), Mansfield; Lee (1996); Klevorick et al. (1995); Cohen et al. (2002); D'Este; Iammarino (2010).

6. Montante de financiamento às atividades de pesquisa nas universidades: Mansfield; Lee (1996).

Portanto, as especificidades intrínsecas aos grupos e às empresas somam-se aos aspectos econômicos e sociais das localidades como aspectos fundamentais para o entendimento das interações realizadas. A consideração de tais peculiaridades permite entender que ao mesmo tempo em que fatores específicos da localidade corroboram para a relevância da proximidade na geração de relacionamentos com vistas à inovação, outros fatores apontam para outras necessidades mais prementes nesse mesmo objetivo.

O intuito deste trabalho será o de analisar os diferenciais locacionais nos padrões de interação nas distintas grandes áreas de pesquisa dos grupos, na instituição à qual o grupo está fundado, nas empresas classificadas por capacitação tecnológica e nos canais de relacionamento estabelecidos nas interações, dando atenção para demais variáveis já identificadas como 
relevantes em demais trabalhos da área para o caso brasileiro (Garcia et al., 2011; Garcia et al., 2014).

\section{Base de dados e metodologia}

Foi utilizada uma tabulação especial de dados relativos às interações realizadas entre grupos de pesquisa cadastrados no CNPq - oriundos do Diretório dos Grupos de Pesquisa (DGP) e de empresas - para o Censo do biênio de 2008 4,5. Essa tabulação envolve uma descrição pormenorizada das interações realizadas entre grupos de pesquisa e o setor produtivo e suas características, muitas das quais serão utilizadas e pontuadas na explicação do modelo econométrico sugerido. Somam-se à tabulação especial do DGP informações referentes a aspectos econômicos, populacionais e de localização geográfica dos municípios das empresas. Ademais, foi calculada a distância euclidiana entre os agentes que interagiram. Essas informações serão detalhadas mais à frente em momento oportuno.

A base do DGP constitui o inventário dos grupos de pesquisa em atividade no país, abrangendo informações sobre recursos humanos, linhas de pesquisa, área do conhecimento, setores de atividade, produção científica e tecnológica dos pesquisadores, além dos padrões de interação com o setor produtivo. Esses grupos estão localizados em universidades, instituições isoladas de ensino superior, institutos de pesquisa científica, institutos tecnológicos, laboratórios de pesquisa e desenvolvimento de empresas estatais ou ex-estatais, e algumas organizações não governamentais com atuação em pesquisa. O DGP é o conjunto de informações mais amplo sobre as interações U-E no Brasil disponível atualmente. Contudo, por ser resultado de informações voluntárias fornecidas pelos líderes dos grupos, não correspondem, necessariamente, à totalidade das interações U-E existentes no país.

Uma primeira observação da concentração geográfica dessas interações é apresentada abaixo. Na Figura $1^{a}$, pode ser vista a média da distância das

4 Para este artigo foram acessados os microdados do DGP do Censo de 2008 oriundos do Projeto MCT/FINEP "Metodologia de Avaliação dos Resultados de Conjuntos de Projetos Apoiados por Fundos de Ciência, Tecnologia e Inovação (C,T\&I)".

5 O Diretório dos Grupos de Pesquisa possui censos bianuais a partir de 2000, sendo o último disponibilizado para o ano de 2012. A base de dados utilizada aqui é, portanto, defasada em dois censos (2010 e 2012), mas é justificada sua utilização justamente porque foram disponibilizados os microdados apenas para o ano de 2008. 
interações dos grupos de pesquisa de cada microrregião brasileira, e, na Figura $1 \mathrm{~b}$, a mesma metodologia é aplicada para as empresas de cada microrregião. A distância das interações é calculada como a distância euclidiana entre os municípios do grupo de pesquisa e da unidade do setor produtivo que interagiram. A escolha pelo recorte geográfico microrregional é para facilitar a visibilidade gráfica e o entendimento. As microrregiões representadas em branco não possuem nenhum grupo de pesquisa (Figura 1a) ou empresa (Figura 1b) que estabelecem interação. $\bigcirc$ aumento do gradiente representa o aumento da média da distância das interações.

Figura 1 (a) Distância média das interações dos grupos de pesquisa (microrregião);

(b) Distância média das interações das empresas (microrregião)

(a)

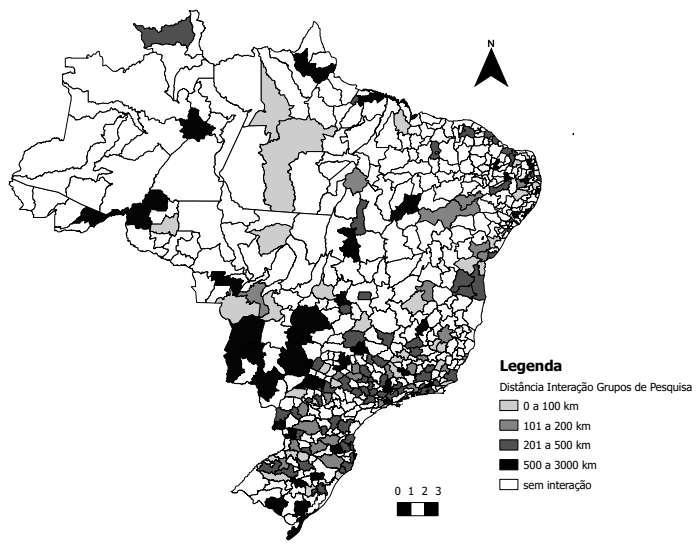

(b)

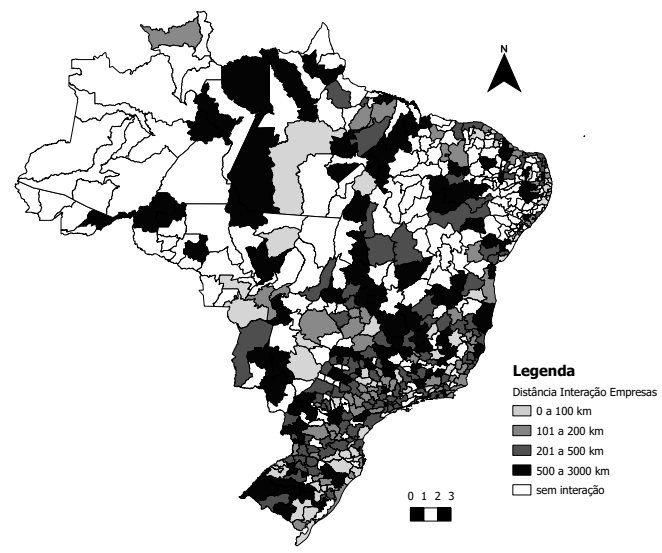

Fonte: Elaboração própria a partir do Diretório dos Grupos de Pesquisa do CNPq. 
Em suma, 30,64\% das microrregiões possuem grupos de pesquisa que interagem, e $62,18 \%$ possuem empresas interativas, o que já aponta uma primeira evidência da diferença na concentração geográfica dos agentes interativos. Nota-se ainda uma diferença na distância média empreendida em relacionamentos dos agentes: considerando apenas as microrregiões que possuem agentes interativos, na média, os grupos de pesquisa realizam interação a uma distância de $358,25 \mathrm{~km}$, enquanto empresas têm o padrão de interagir a distâncias maiores, em uma média de $510,91 \mathrm{~km}$.

A comparação gráfica das figuras mostra ainda padrões diferenciados de concentração geográfica: $60,24 \%$ das microrregiões que possuem grupos de pesquisa e $59,15 \%$ das microrregiões que possuem empresas que interagem estão nas regiões Sudeste e Sul. Além disso, 41,57\% das microrregiões dessas regiões federativas possuem grupos de pesquisa que interagem, enquanto nas demais regiões a proporção de microrregiões que possuem grupos de pesquisa interativos é de apenas $21,11 \%$. Na realidade das empresas, $81,17 \%$ das microrregiões na região Sudeste e Sul possuem tais agentes realizando interações, enquanto o valor é de 46,88\% para as microrregiões das demais regiões federativas.

Na Tabela 1 é apresentado um levantamento descritivo com foco na localização por região geográfica do grupo de pesquisa e da empresa que interagem em um total de 6558 interações cadastradas.

Tabela 1 Estatísticas descritivas básicas - Censo biênio 2008

\begin{tabular}{lr|r|r|r|r|r}
\hline Grupo de pesquisa & $\begin{array}{r}\text { Centro- } \\
\text { - Oeste }\end{array}$ & Nordeste & Norte & Sudeste & Sul & Brasil \\
\hline Número de relacionamentos & 367 & 1026 & 259 & 3005 & 1901 & 6558 \\
\hline \% total & $5,59 \%$ & $15,64 \%$ & $39,40 \%$ & $45,82 \%$ & $28,99 \%$ & $100 \%$ \\
\hline $\begin{array}{l}\text { Distância média dos } \\
\text { relacionamentos (Km) }\end{array}$ & 343,93 & 413,16 & 521,06 & 334,16 & 431,63 & 382,70 \\
\hline Desvio-padrão (Km) & 577,39 & 716,28 & 923,24 & 575,34 & 794,22 & 674,70 \\
\hline Empresas & $\begin{array}{r}\text { Centro- } \\
-0 \text { Noste }\end{array}$ & Nordeste & Norte & Sudeste & Sul & Brasil \\
\hline Número de relacionamentos & 454 & 914 & 263 & 3230 & 1697 & 6558 \\
\hline \% total & $6,92 \%$ & $13,94 \%$ & $4,01 \%$ & $49,25 \%$ & $25,88 \%$ & $100 \%$ \\
\hline $\begin{array}{l}\text { Distância média dos } \\
\text { relacionamentos (Km) }\end{array}$ & 535,8 & 240,59 & 577,87 & 394,41 & 365,72 & 382,70 \\
\hline Desvio-padrão (Km) & 675,89 & 541,62 & 994,59 & 617,12 & 796,16 & 674,70 \\
\hline
\end{tabular}

Fonte: Elaboração própria a partir do Diretório dos Grupos de Pesquisa do CNPq. 
As informações da tabela corroboram o viés concentrador das interações nas regiões Sudeste e Sul, apontando ainda uma diferença nas distâncias médias das interações estabelecidas pelos grupos de pesquisa e pelas empresas nas distintas regiões geográficas. Essas informações, somadas às informações extraídas da Figura 1, mostram uma conformação de concentração geográfica dos agentes não só em regiões geográficas mas também em microrregiões específicas, principalmente para os grupos de pesquisa, bem como padrões distintos de distância na interação dos agentes.

O alto desvio-padrão apresentado na Tabela 1, porém, deixa claro que há uma variabilidade considerável das informações, o que destaca a importância de outros determinantes na explicação da relevância da distância geográfica no relacionamento entre os agentes. É justamente a verificação da relevância desses distintos determinantes o motivo de se proceder com a proposta de estudo deste artigo.

O exercício metodológico terá como base a análise econométrica por meio do modelo Tobit, proposto inicialmente por Tobin (1958) e também conhecido como modelo de regressão censurado. $\bigcirc$ mesmo é designado para estimar relacionamentos lineares entre variáveis quando existe uma censura superior ou inferior na variável dependente. Esse é justamente o caso da variável dependente, a distância locacional entre os grupos de pesquisa e empresas industriais de cada interação analisada. Das 6.558 interações analisadas, 2.644 (40,32\%) foram realizadas entre grupos de pesquisa e empresas do mesmo município (ou seja, interação com distância locacional nula), o que configura um truncamento no limite inferior.

Será utilizada a seguinte especificação econométrica:

$$
\begin{aligned}
\text { LnDistância }_{i} & =\beta_{1}{\text { Características } G P_{i}+} \beta_{2} \text { Característicaempresa }_{j} \\
& +\beta_{3} \text { Característicalocacionalempresa }_{j}+\beta_{4} \text { relacionamento }_{i j}
\end{aligned}
$$

Ou seja, a proposição do modelo considera que os determinantes da distância geográfica alcançada na interação são dependentes das características dos grupos de pesquisa, das características das empresas e das características da localidade das empresas. As variáveis são descritas da seguinte forma:

\section{Variável dependente}

Distância: corresponde à distância euclidiana entre os municípios-sede da 
instituição que abriga o grupo de pesquisa e o município-sede da unidade do setor produtivo que interagiram. Serão estimados dois modelos, um considerando a distância linear e o outro considerando o logaritmo da distância;

\section{Variáveis independentes "características grupo de pesquisa"}

a) Tempo de atuação do grupo de pesquisa;

b) Número de doutores;

c) Fator Ciência GP: fator obtido pelo método de Análise Fatorial (AF) ${ }^{6}$ para variáveis relativas aos grupos de pesquisa que interagiram, todas disponibilizadas na base DGP. As variáveis utilizadas para a definição do indicador $^{7}$ são as seguintes, todas elas normalizadas para o número de doutores existente nos grupos de pesquisa:

- Quantidade de artigos de circulação nacional publicados;

- Quantidade de artigos de circulação internacional publicados;

- Número de teses defendidas;

- Número de dissertações defendidas.

A definição do fator ciência busca captar a relevância acadêmica e a escala dos grupos de pesquisa, aspecto destacado como relevante nos trabalhos de Mariani (2004), Mansfield (1995), Maia (2005) e Garcia et al. (2014). Considerando sua relevância, será destacada como variável de controle para os objetivos principais do artigo.

d) Tipo Instituição: variável dummy de controle dos tipos de instituição às quais os grupos de pesquisa estão filiados, segundo classificação da base DGP. Os tipos de instituição classificados são os seguintes:

- Ensino superior público federal;

- Ensino superior público estadual;

- Ensino superior privado;

- Setor empresarial público: engloba empresas do setor governamental público estadual, setor empresarial público federal e setor empresarial público estadual ${ }^{8}$.

6 Para mais informações sobre o método de Análise Fatorial sugere-se a leitura de Mingoti (2005).

7 A proporção acumulada de explicação do fator 1 obtido pelo método de AF para o conjunto de variáveis sugeridas foi de $123,23 \%$, o que corrobora sua validade para o objetivo proposto, qual seja, de expressar a relevância científica do grupo de pesquisa. O cálculo da análise fatorial encontra-se no anexo do artigo.

8 Optou-se por trabalhar agrupando essas classificações pelo pequeno número de empre- 
e) Grande Área: variável dummy para as grandes áreas científicas já descritas na Tabela 1. A sua definição busca captar a relevância das áreas de atuação dos grupos de pesquisa nos determinantes da distância de interação, assim como já observado em Jaffe (1989), Klevorick et al. (1995) e Cohen et al. (2002).

f) Regiões: variável dummy para as grandes regiões do Brasil.

\section{Variável independente "características empresas"}

g) Tipo de empresas: a classificação dos tipos de empresas foi estabelecido de acordo com a capacitação e apropriabilidade tecnológica aos moldes de Pavitt (1984), consideradas as especificidades brasileiras levantadas no trabalho de Campos e Ruiz (2009). Como algumas interações não são estabelecidas diretamente com empresas da indústria de transformação, à classificação de Campos e Ruiz (2009) foram inseridas categorias definidas pelos autores desse trabalho (categorias 5 a 7 ).

I. Dominada por fornecedores;

II. Fornecedores especializados;

III. Intensivos em escala;

IV. Science based;

V. Comércio e prestação de serviços;

VI. Administração pública;

VII. Intermediação financeira;

VIII. Classificação não definida (não constava na base).

A observação da variável pretende captar a relevância encontrada nos trabalhos de Beise e Stahl (1999); Harmon et al. (1997); Lemarié; Mangematin; Torre (2001); Mariani (2004).

\section{Variáveis independentes "características locacionais empresas"}

Utilizadas para controle do modelo.

h) Fator Econômico Emp.: fator obtido pelo método de AF para variáveis relativas à escala populacional, econômica e capacitação industrial dos municípios-sede das empresas que realizam interação. As variáveis utilizadas

sas desses setores. Conjuntamente elas totalizam apenas 46 empresas $(0,70 \%$ do universo amostral). 
para a definição do indicador ${ }^{9}$ são as seguintes:

- PIB municipal, ano 2008. Fonte: IBGE;

- PIB municipal per capita, ano 2008. Fonte: IBGE;

- Escala industrial: baseado em Lima (2012), utilizaram-se dados a partir do IBGE considerando a seguinte classificação: 01 para municípios industriais irrelevantes (trabalho industrial < 1.000); 02 para municípios industriais intermediários (entre 1.000 e 10.000); e 03 para municípios industriais relevantes $(\geq 10.000)$.

A definição do fator econômico urbano busca captar a escala urbana e capacitação econômica da localidade-sede da empresa, aspecto destacado como relevante nos trabalhos de Varga (1997); Santos (2009); Bittencourt; Rapini (2009); Garcia et al. (2011), Bittencourt et al. (2012) e Garcia et al. (2014).

i) Logaritmo da população municipal: variável utilizada para captar o efeito da aglomeração urbana do município;

j) Índice de especialização: baseado em Haddad (1989), o índice de especialização varia entre zero e um; quanto mais próximo ao limite superior, maior o grau de especialização em atividades ligadas a um determinado setor industrial no município em comparação ao padrão nacional. $O$ índice de especialização foi calculado por meio da densidade dos empregos setoriais nos setores IBGE.

A consideração das variáveis estruturais da localidade procuram captar os efeitos considerados em Varga (1997); Santos (2009); Bittencourt; Rapini (2009); Bittencourt et al. (2012); Garcia et al. (2011); Garcia et al. (2014) e servem como variável de controle para o modelo.

\section{Variável independente "relacionamento"}

k) Relacionamento: variável dummy para os diferentes tipos de relacionamento descritos na base DGP. O intuito da variável é considerar os resultados de Monjon e Waelbroeck (2003), Arza e Vasquez (2010) e Brostrom (2010), procurando captar diferenças de distanciamento segundo os distintos tipos de relacionamento possíveis. Para este trabalho, é conside-

9 A proporção acumulada de explicação do fator 1 obtido pelo método de AF para o conjunto de variáveis sugeridas foi de $169,63 \%$, o que corrobora sua validade para o objetivo proposto, qual seja, de expressar a escala urbano-econômica do município-sede do grupo de pesquisa. O cálculo da análise fatorial encontra-se no anexo do artigo. 
rada a classificação sugerida em Arza e Vasquez (2010) e Fernandes et al. (2010), associando-a com os tipos de relacionamento especificados na base DGP. Em suma, a conexão definida neste trabalho para a classificação dos autores supracitados e a definição da base DGP é apresentada no quadro 1 abaixo.

Quadro 1 Tipos de relacionamento entre grupos de pesquisa e empresas

\begin{tabular}{|c|c|c|c|c|c|}
\hline $\begin{array}{l}\text { Classificação } \\
\text { Arza e Vas- } \\
\text { quez (2010) / } \\
\text { Fernandes } \\
\text { et al. (2010) }\end{array}$ & \begin{tabular}{|l} 
Canal \\
bidirecional
\end{tabular} & $\begin{array}{l}\text { Canal } \\
\text { prestação } \\
\text { de serviços }\end{array}$ & $\begin{array}{l}\text { Canal } \\
\text { comercial }\end{array}$ & $\begin{array}{l}\text { Insumos } \\
\text { materiais }\end{array}$ & Outros \\
\hline $\begin{array}{l}\text { Descrição } \\
\text { Relaciona- } \\
\text { mento Base } \\
\text { DGP }\end{array}$ & $\begin{array}{l}\text { 1. Pesquisa de } \\
\text { curto prazo; } \\
\text { 2. Pesquisa de } \\
\text { longo prazo. }\end{array}$ & $\begin{array}{l}\text { 1. Engenharia } \\
\text { não-rotineira; } \\
\text { 2. Desenvol- } \\
\text { vimento de } \\
\text { software; } \\
\text { 3. Consultoria } \\
\text { técnica; } \\
\text { 4. Treinamento } \\
\text { de pessoal. }\end{array}$ & $\begin{array}{l}\text { 1. Transfe- } \\
\text { rência de } \\
\text { tecnologia. }\end{array}$ & $\begin{array}{l}\text { 1. Fornecimen- } \\
\text { to de insumos } \\
\text { materiais para } \\
\text { pesquisa. }\end{array}$ & $\begin{array}{l}\text { 1. Outros tipos } \\
\text { de relaciona- } \\
\text { mento. }\end{array}$ \\
\hline
\end{tabular}

Fonte: Elaboração própria a partir do DGP do CNPq, Arza e Vasquez (2010) e Fernandes et al. (2010).

Cabe lembrar que a base DGP permite a classificação de até três tipos de relacionamentos estabelecidos entre os agentes. A opção metodológica utilizada nesse artigo foi analisar o primeiro dos relacionamentos mencionados por entender que ele se apresenta como o mais relevante na observação do líder do grupo de pesquisa. ${ }^{10}$

\section{Variável independente "remuneração"}

l) Remuneração: variável dummy para os diferentes tipos de remuneração descritos na base DGP. Como existe classificação para dez tipos de remuneração, optou-se por uma classificação mais restritiva, em busca de agregar as remunerações com características em comum conforme Rapini et al. (2014). A classificação adotada segue o quadro abaixo.

10 Entende-se que ser esta é uma opção metodológica mais prudente do que utilizar as três classificações, aumentando o número de observações, porque é usual existir uma classificação hierárquica do líder do grupo de pesquisa no momento da resposta. 
Quadro 2 Tipos de relacionamento entre grupos de pesquisa e empresas

\begin{tabular}{|c|c|c|c|c|c|c|}
\hline $\begin{array}{l}\text { Classifi- } \\
\text { cação }\end{array}$ & $\begin{array}{l}\text { Recurso } \\
\text { Financeiro }\end{array}$ & $\begin{array}{l}\text { Outro tipo } \\
\text { de recurso }\end{array}$ & $\begin{array}{l}\text { Bolsas e } \\
\text { Transf. RH }\end{array}$ & Risco & $\begin{array}{l}\text { Insumos } \\
\text { materiais }\end{array}$ & Outros \\
\hline $\begin{array}{l}\text { Descrição } \\
\text { Remunera- } \\
\text { ção Base } \\
\text { DGP }\end{array}$ & $\begin{array}{l}\text { 1. Transfe- } \\
\text { rência de } \\
\text { recursos } \\
\text { financeiros. }\end{array}$ & $\begin{array}{l}\text { 1. Parceria } \\
\text { com trans- } \\
\text { ferência de } \\
\text { recursos de } \\
\text { qualquer } \\
\text { espécie } \\
\text { nos dois } \\
\text { sentidos. }\end{array}$ & $\begin{array}{l}\text { 1. Forneci- } \\
\text { mento de } \\
\text { bolsas para } \\
\text { o grupo pelo } \\
\text { parceiro; } \\
\text { 2. Transfe- } \\
\text { rência física } \\
\text { temporária } \\
\text { de RH. }\end{array}$ & $\begin{array}{l}\text { 1. Parceria } \\
\text { sem a trans- } \\
\text { ferência de } \\
\text { recursos de } \\
\text { qualquer } \\
\text { espécie, } \\
\text { envolvendo } \\
\text { exclusiva- } \\
\text { mente rela- } \\
\text { cionamento } \\
\text { de risco. }\end{array}$ & $\begin{array}{l}\text { 1. Transfe- } \\
\text { rência de } \\
\text { insumos } \\
\text { materiais. }\end{array}$ & $\begin{array}{l}\text { 1. Outras } \\
\text { formas de } \\
\text { remune- } \\
\text { ração que } \\
\text { não se } \\
\text { enquadrem } \\
\text { em nenhu- } \\
\text { ma das } \\
\text { anteriores. }\end{array}$ \\
\hline
\end{tabular}

Fonte: Elaboração própria a partir do DGP do CNPq.

Assim como para os tipos de relacionamento, a base DGP também permite a classificação de até três tipos de remuneração. Optou-se, portanto, pela mesma escolha metodológica utilizada para os tipos de relacionamento.

\section{Resultados e discussão}

Uma apresentação das informações de estatística descritiva inicial é feita na Tabela 2 para variáveis selecionadas do modelo econométrico. $\bigcirc$ padrão de apresentação segue o mesmo da Tabela 1, destacando o número de observações, média e desvio-padrão da distância das interações.

Tabela 2 Estatísticas descritivas variáveis selecionadas

\begin{tabular}{l|r|r|r|r}
\hline & $\begin{array}{r}\text { Relaciona- } \\
\text { mentos }\end{array}$ & \% total & $\begin{array}{r}\text { Média da dis- } \\
\text { tância (Km) }\end{array}$ & $\begin{array}{r}\text { Desvio- } \\
\text { padrão (Km) }\end{array}$ \\
\hline Tipo de Instituição & & & & \\
\hline ESPubFederal(ESPF) & 6136 & $93,57 \%$ & 391,27 & 692,61 \\
\hline ESPubEstadual (ESPE) & 288 & $4,39 \%$ & 181,05 & 361,82 \\
\hline ESPrivado (ESPriv) & 75 & $1,14 \%$ & 153,09 & 457,02 \\
\hline SEPúblico (SEPub) & 59 & $0,92 \%$ & 916,33 & 1033,95 \\
\hline Grande Área de Pesquisa & \multicolumn{5}{c}{} & \\
\hline Ciências Agrárias & 1.367 & $20,84 \%$ & 580,32 & 826,6 \\
\hline Ciências Biológicas & 532 & $8,11 \%$ & 404,8 & 664,81 \\
\hline
\end{tabular}




\begin{tabular}{|c|c|c|c|c|}
\hline & $\begin{array}{r}\text { Relaciona- } \\
\text { mentos }\end{array}$ & $\%$ total & $\begin{array}{r}\text { Média da dis- } \\
\text { tância (Km) }\end{array}$ & $\begin{array}{r}\text { Desvio- } \\
\text { padrão }(\mathrm{Km})\end{array}$ \\
\hline Ciências da Saúde & 578 & $8,81 \%$ & 267,08 & 587,74 \\
\hline Ciências Exatas e da Terra & 865 & $13,19 \%$ & 388,94 & 706,27 \\
\hline Ciências Humanas & 396 & $6,04 \%$ & 287,43 & 600,49 \\
\hline Ciências Sociais Aplicadas & 424 & $6,47 \%$ & 189,01 & 480,84 \\
\hline Engenharias & 2.351 & $35,85 \%$ & 344,39 & 634,15 \\
\hline Linguística, Letras e Artes & 45 & $0,69 \%$ & 146,58 & 436,31 \\
\hline \multicolumn{5}{|l|}{ Tipo de empresas } \\
\hline Dominada por fornecedores & 1018 & $15,52 \%$ & 423,82 & 690,16 \\
\hline Fornecedores especializados & 630 & $9,60 \%$ & 479,82 & 731,06 \\
\hline Intensivos em escala & 366 & $5,58 \%$ & 449,8 & 631,62 \\
\hline Science Based & 1078 & $16,43 \%$ & 537,22 & 838,07 \\
\hline Comércio e prestação de serviços & 1761 & $26,84 \%$ & 296,34 & 606,82 \\
\hline Administração pública & 758 & $11,55 \%$ & 344,91 & 647,19 \\
\hline Intermediação financeira & 50 & $0,76 \%$ & 428,68 & 644,26 \\
\hline Sem classificação definida & 899 & $13,70 \%$ & 250,53 & 576,65 \\
\hline \multicolumn{5}{|l|}{ Tipo de Relacionamento } \\
\hline Canal bidirecional & 4396 & $67,03 \%$ & 414,73 & 712,48 \\
\hline Canal de serviços & 765 & $11,67 \%$ & 288,71 & 615,81 \\
\hline Canal comercial & 751 & $11,45 \%$ & 336,83 & 630,75 \\
\hline Canal insumos materiais & 272 & $4,15 \%$ & 411,9 & 704,65 \\
\hline Outros & 374 & $5,70 \%$ & 269,29 & 536,06 \\
\hline \multicolumn{5}{|l|}{ Tipo de Remuneração } \\
\hline Recursos financeiros & 2815 & $42,92 \%$ & 442,95 & 710,35 \\
\hline Outro tipo de recurso & 240 & $3,66 \%$ & 316,75 & 651,42 \\
\hline Bolsas e RH & 790 & $12,05 \%$ & 303,41 & 635,07 \\
\hline Risco & 1050 & $16,01 \%$ & 296,09 & 650,28 \\
\hline Insumos materiais & 944 & $14,39 \%$ & 392,94 & 688,32 \\
\hline Outros & 719 & $10,96 \%$ & 368,90 & 672,26 \\
\hline
\end{tabular}

Fonte: Elaboração própria.

Pode-se observar a predominância de grupos de pesquisa localizados em instituições públicas de ensino superior federal (ESPF) operando principalmente nas grandes áreas de pesquisa Ciências Agrárias e Engenharias (somados são 56,12\% das observações). Tais informações denotam a concentração e relevância do governo na intensificação das interações no SNI 
brasileiro (via relevância das instituições de ensino superior federal) e o viés científico nacional agrário, porém com forte interação na grande área de Engenharia.

Esses grupos operam com empresas de setores distintos, com predominância para empresas de comércio e prestação de serviços baseadas em ciência e dominada por fornecedores. As interações realizadas por esses agentes são em $67,03 \%$ dos casos realizadas via canal bidirecional de interação, sendo que em $42,92 \%$ dos casos são remunerados via recursos financeiros.

Aqui se apresenta uma dinâmica paradoxal das interações U-E no âmbito nacional. Apesar das interações tratarem em sua maioria de pesquisas científicas de curto ou longo prazo (canal bidirecional), grande parte delas é realizada com empresas ligadas ao comércio e à prestação de serviços (1117 interações de canal bidirecional são realizadas para empresas dessa classificação), que não representam o lócus principal do ambiente inovativo industrial. Um aprofundamento no entendimento desse comportamento deve ser observado em trabalhos futuros.

Por fim, a observação das médias e desvio-padrão das distintas classificações denota assim como na Tabela 1 a grande variabilidade das informações, corroborando a necessidade do controle via modelo econométrico para o entendimento da significância dos distintos determinantes.

A estimação do modelo Tobit foi realizada assumindo a homocedasticidade dos erros, pois, conforme Maddala (1983) e Powell (1984), o efeito marginal calculado no modelo heterocedástico é geralmente muito similar àquele obtido pelo modelo que assume homocedasticidade. De qualquer forma, um modelo com correção pela matriz robusta de White também foi estimado, e os resultados encontrados demonstram que a estatística $t$ dos parâmetros estimados não possui mudança significativa que modifique a significância dos parâmetros do modelo. O software utilizado foi o Stata 12 . Apresentam-se abaixo os resultados e a discussão para o modelo proposto, considerando a distância linear e a distância em logaritmo.

A estatística qui-quadrado aponta a validade das estimações, e os resultados apresentados nos valores e significância dos parâmetros corroboram, em grande parte, os resultados destacados por trabalhos da área. Além disso, a comparação entre os modelos de variável dependente linear e logarítmica são bastante próximos, com diferença de significância estatísticas apenas nos casos dos tipos de empresa Administração Pública e Intermediação Financeira. 
Tabela 3 Modelo econométrico distância interações

\begin{tabular}{|c|c|c|}
\hline Variáveis & Modelo Distância Linear & Modelo Distância em Logaritmo \\
\hline \multicolumn{3}{|c|}{ Características Grupos de Pesquisa } \\
\hline Tempo de atuação do Grupo & $-2,37$ & 0,004 \\
\hline Doutores & $2,73^{* *}$ & $0,028^{*}$ \\
\hline Fator_ciênciaGP & $187,59 *$ & $0,358^{*}$ \\
\hline \multicolumn{3}{|l|}{ Dummy tipo instituição } \\
\hline ESPubEstadual (ESPE) & $-348,26 *$ & $-1,252^{*}$ \\
\hline ESPrivado (ESPriv) & $-281,78^{* *}$ & $-1,656^{*}$ \\
\hline SEPúblico (SEPub) & $469,30^{*}$ & $1,797^{* *}$ \\
\hline \multicolumn{3}{|l|}{ Dummy Grande Área } \\
\hline Ciências Biológicas & $-185,48^{*}$ & $-0,729 *$ \\
\hline Ciências da Saúde & $-453,87^{*}$ & $-2,382^{*}$ \\
\hline Ciências Exatas e da Terra & $-196,79 *$ & $-1,100^{*}$ \\
\hline Ciências Humanas & $-124,71^{* *}$ & $-0,491^{* * *}$ \\
\hline Ciências Sociais Aplicadas & $-468,79 *$ & $-2,418^{*}$ \\
\hline Engenharias & $-326,45^{*}$ & $-1,531^{*}$ \\
\hline Linguística, Letras e Artes & $-734,40^{*}$ & $-4,204^{*}$ \\
\hline \multicolumn{3}{|l|}{ Dummy Regiões } \\
\hline Sul & $106,24^{*}$ & $0,280 * *$ \\
\hline Nordeste & $210,15^{*}$ & $0,079 * *$ \\
\hline Centro-Oeste & $-111,64^{* * *}$ & $-1,448^{*}$ \\
\hline Norte & $202,49 *$ & $1,081^{*}$ \\
\hline \multicolumn{3}{|l|}{ Características Empresas } \\
\hline \multicolumn{3}{|l|}{ Dummy Tipo de Empresas } \\
\hline Fornecedores especializados & $192,05^{*}$ & $0,337^{* * *}$ \\
\hline Intensivos em escala & $209,85^{*}$ & $0,916^{*}$ \\
\hline Science Based & $203,03^{*}$ & $0,422^{* *}$ \\
\hline $\begin{array}{l}\text { Comércio e prestação de } \\
\text { serviços }\end{array}$ & $-134,98^{*}$ & $-1,265^{*}$ \\
\hline Administração pública & $-10,33$ & $-0,565^{*}$ \\
\hline Intermediação financeira & $205,66^{* * *}$ & 0,631 \\
\hline Sem classificação definida & $-244,75^{*}$ & $-1,662^{*}$ \\
\hline \multicolumn{3}{|c|}{ Características Locacionais das Empresas } \\
\hline Fator_econômico empresa & $333,53^{*}$ & $2,170 *$ \\
\hline Log população & $-231,21^{*}$ & $-1,861^{*}$ \\
\hline Índice especialização & $1326,44^{*}$ & $2,962^{*}$ \\
\hline
\end{tabular}




\begin{tabular}{lrr}
\hline Variáveis & Modelo Distância Linear & Modelo Distância em Logaritmo \\
\hline \multicolumn{2}{l}{ Características dos Relacionamentos } & \\
\hline Dummy Relacionamentos & & \\
\hline Canal de serviços & $-130,47^{*}$ & $-0,666^{*}$ \\
\hline Canal comercial & $119,04^{* * *}$ & $-0,248$ \\
\hline Canal insumos materiais & $-168,10^{*}$ & $0,640^{* *}$ \\
\hline Sem class.definida & $-175,37^{*}$ & $-0,389^{* * *}$ \\
\hline Dummy Remunerações & $-225,38^{*}$ & $-0,886^{*}$ \\
\hline Outros tipos de recursos & $-130,55^{*}$ & $-1,238^{*}$ \\
\hline Bolsas e RH & 9,15 & $-0,593^{*}$ \\
\hline Risco & $-121,94^{* * *}$ & $-0,228$ \\
\hline Insumos materiais & $1373,37^{*}$ & $-0,748^{* *}$ \\
\hline Outros & 1095,56 & $14,280^{*}$ \\
\hline Constante & 0,00 & 1339,88 \\
\hline LR (qui-quadrado) & $-33498,01$ & 0,00 \\
\hline Prob > qui-quadrado & 0,0161 & $-13001,41$ \\
\hline Log-Likelihood & 0,0490 \\
\hline Pseudo R2 & &
\end{tabular}

Fonte: Elaboração própria.

Observação: Significante a 1\% $\left({ }^{*}\right), 5 \%\left({ }^{* *}\right)$ e $10 \%\left({ }^{* * *}\right)$.

Variável dependente: Distância geográfica.

Período: censo 2008 DGP.

Número de observações: 6558.

Interação comparativa (dummies): Ensino Superior Público Federal (ESPF), Ciências Agrárias, Relacionamento canal bidirecional; Indústria Dominada por fornecedores; Recursos financeiros; Região Sudeste.

A escala e relevância científica dos grupos de pesquisa, externadas pelas variáveis número de doutores e Fator_CiênciaGP, tem impacto direto sobre as possibilidades de interação desses grupos com empresas. Segundo o modelo, o incremento de escala e de capacitações científicas do grupo permite que o mesmo consiga realizar interações com empresas localizadas a maiores distâncias, justamente porque o conhecimento dos membros desses grupos pode se tornar mais importante do que a proximidade locacional que a empresa possa ter com outros grupos de pesquisa. Esse resultado está em consonância com os resultados destacados em Mariani (2004), Mansfield (1995), Maia (2005) e Garcia et al. (2014). Contudo, é interessante notar que o tempo de existência do 
grupo de pesquisa não apresenta relevância para as possibilidades de interação desses grupos.

Em relação aos resultados para as dummies sobre o tipo de instituição, a comparação é feita em relação aos grupos de pesquisa localizados em instituições de ensino superior público federal (ESPF). Assim, os parâmetros encontrados sugerem que há significância estatística que diferencia esses grupos daqueles localizados em instituição de ensino superior público estadual (ESPE), ensino superior privado (ESPRIV) e setor empresarial público (SEPub). No caso dos dois primeiros grupos de instituições, o parâmetro é negativo, destacando que grupos de pesquisa localizados nessas universidades realizam interações com empresas mais próximas (vis a vis grupos localizados em instituições de ensino superior público federal). O resultado contrário é válido para a instituição setor empresarial público federal; os grupos de pesquisa cadastrados nessas instituições estabelecem pesquisa a distâncias maiores que os cadastrados nas instituições de comparação.

Em relação às instituições SEPub, deve-se considerar que 38 interações da base (ou seja, 64,41\% das interações desse tipo de instituição) correspondem à atuação de grupos de pesquisa cadastrados na Empresa Brasileira de Pesquisa Agropecuária (EMBRAPA), sediados em municípios da Região Norte (estados do Acre, Amazonas, Pará e Roraima). Esses grupos desenvolvem interações com empresas localizadas em distâncias consideráveis pela própria especificidade geográfica da região.

Mais interessante é notar a relevância das instituições de ensino superior públicas federais no contexto histórico da evolução do ensino superior brasileiro, denotando como desempenham papel fundamental na evolução da ciência, tecnologia e inovação em território nacional. Isso porque além de ser parte majoritária da amostra (93,57\% dos GP estão nessas instituições), realizam interações a distâncias estatisticamente mais distantes que as demais instituições de ensino nacionais.

As dummies estabelecidas para as grandes áreas do conhecimento reforçam os resultados sobre a diferenciação no padrão de interação dos agentes, com a indicação de maiores distâncias na interação para a grande área de Ciências Agrárias. Esse resultado é explicado pela capacitação agrária intrínseca ao desenvolvimento econômico brasileiro e pelas pesquisas desenvolvidas pela EMBRAPA (Suzigan; Albuquerque, 2011). A evolução histórica desse viés econômico agrário solidificou a capacitação científica das instituições e dos grupos de pesquisa especializados nessa grande área. 
Para efeito de comparação, o fator de qualidade científica (Fator_CienciaGP) médio dos grupos de pesquisa da Grande Área Ciências Agrárias é 0,389, enquanto a média das demais grandes áreas é -0,014.

A variável de controle das grandes regiões dos grupos de pesquisa aponta os resultados já inicialmente verificados na Tabela 1: grupos de pesquisa localizados nas regiões, Sul, Norte e Nordeste interagem a distâncias maiores que grupos da região Sudeste; e grupos localizados na região Centro-oeste interagem a distâncias menores que os da região Sudeste.

Considerando as características das empresas classificadas segundo a capacitação tecnológica e, em alguns casos, classificação própria ${ }^{11}$, o modelo indica que as empresas nos setores industriais de fornecedores especializados, intensivos em escala e science based tendem a estabelecer relacionamentos a distâncias maiores que empresas de setores industriais dominados por fornecedores ${ }^{12}$. Em contrapartida, empresas da administração pública e comércio e prestação de serviços estabelecem interações a distâncias menores se comparadas com empresas dos setores dominados por fornecedores. Em suma, os resultados apontam que a escala produtiva (firmas intensivas em escala), a especialidade dos ativos comercializados (fornecedores especializados) e o conteúdo tecnológico das firmas (science based firms) sinalizam a possibilidade de estabelecimento de interações a distâncias maiores.

Com respeito às características do município das empresas, pode-se verificar que há relevância dos fatores econômicos e urbanos, visto que o resultado dos coeficientes do fator econômico, do índice de especialização e do logaritmo da população apresentam significância estatística e sinal condizente com a literatura. Em suma, empresas localizadas em municípios com maior capacidade de desenvolvimento econômico (Fator_econômico empresa) tendem a ter maior interação com grupos de pesquisa a maiores distâncias; empresas localizadas em municípios com maior especialização produtiva (Índice de especialização mais próximo da nulidade) tendem a interagir a distâncias menores. E, por último, a maior densidade populacional (calculada pelo logaritmo da população) tende a aumentar as possibilidades de interações ao nível local.

11 Nessa análise mais uma vez exclui-se a categoria "sem classificação definida".

$12 \bigcirc$ que pode ser explicado pela dinâmica do processo inovativo no setor de serviços, em que os recursos humanos desempenham papel fundamental (Tether; Hipp, 2000), justificando uma maior proximidade entre os agentes e os contatos "face a face". 
Conforme aponta Garcia et al. (2014), esses resultados são congruentes aos destacados pela Nova Geografia Econômica no que tange às economias de aglomeração e diversificação produtiva. O resultado também é similar ao sugerido em Varga (1997), que destaca a importância da concentração espacial de atividades econômicas e da urbanidade para o estabelecimento de interações.

A respeito das dummies estabelecidas para os diferentes tipos de relacionamento, os resultados não são definitivos nos dois modelos propostos. Apenas os relacionamentos "canal de serviços" e "sem classificação definida" apresentaram significância estatística do coeficiente nos dois modelos que permite dizer que suas interações são realizadas a distâncias menores em comparação ao canal bidirecional. Para o caso do relacionamento "insumos materiais", verifica-se que interações por esse canal são realizadas a maiores distâncias do que no canal bidirecional. Aqui cabe discorrer sobre a raiz conceitual da classificação sugerida, em concordância com os trabalhos de Arza e Vasquez (2010) e Fernandes et al. (2010).

O exercício de adequação dos tipos de relacionamento classificados na base DGP dentro dos distintos canais propostos nos textos supracitados tem o intuito de agrupar na mesma classificação relacionamentos que servem às diferentes motivações das empresas e dos grupos de pesquisa. Entende-se que relacionamentos classificados como canal comercial envolvem interações focadas na comercialização de tecnologias já existentes (exemplos são spin-offs, patentes e incubadoras tecnológicas); o canal de serviços envolve a solução de problemas específicos de produção através de relações curtas, realizadas sob demanda específica, como consultorias, treinamento de pessoal, entre outros.

Segundo Morgan (2004), Arundel e Geuna (2004) e Giuliani (2005) a proximidade geográfica é mais importante quando a interação envolve altos níveis de conhecimento tácito e a necessidade de contato pessoal. Por outra via, canais de interação que envolvem conhecimento codificado (como licenças, patentes e contratos de pesquisa) apresentam menor sensibilidade à localidade geográfica (De Fuentes; Dutrénit, 2014).

Nesse contexto, os relacionamentos via canal bidirecional e relacionamentos comerciais são de classificação "conhecimento codificado", enquanto relacionamentos via canal de serviço envolvem um padrão mais próximo ao conhecimento tácito e ao contato pessoal na prestação de serviços. Nos dois primeiros, a interação normalmente envolve regras formais de relacionamento, com interação de longo prazo e fluxo de conhecimento contínuo entre os agentes. 
Esses padrões específicos de comportamento em conjunção com os resultados dos parâmetros identificados no modelo econométrico sugerem que, no caso brasileiro, os resultados são congruentes com os encontrados por Arza e Vasquez (2010) e Brostrom (2010). Interações que envolvem resoluções de problemas para o mercado, com relacionamentos pontuais via prestação de serviços, possuem maior dependência da localidade que interações de longo prazo, que frequentemente envolvem uma rede de relacionamento melhor consolidada e perene.

Já no caso dos relacionamentos para compra de insumos materiais, maiores distâncias no relacionamento são explicadas pelas demandas científicas por parte das empresas e demanda direcionada por licitação, por parte dos grupos. Quando a compra de insumos materiais desenvolvido por um GP é realizada por uma empresa, está atrelada a essa transação as especificidades científicas do produto desenvolvido pelo grupo de pesquisa, com importância minorada da distância entre esses agentes. O fornecimento de um produto por parte de um grupo de pesquisa para uma empresa envolve uma especificidade elevada, muitas vezes com a consideração de escala de produção reduzida e apropriabilidade tecnológica restrita (ou seja, oferta limitada). Para a transação realizada no sentido inverso (grupo de pesquisa compra da empresa), o processo de compra é licitatório, baseado nos determinantes econômicos de menor onerosidade e/ou características específicas do produto, não sendo considerada a distância da oferta.

Os resultados dos tipos de relacionamentos são corroborados pelos resultados alcançados na comparação dos distintos tipos de remuneração. Pode-se notar que interações remuneradas via recursos financeiros são realizadas a distâncias maiores do que as interações realizadas pelos demais tipos de remuneração, com exceção de insumos materiais. Por sua vez, as remunerações via risco e via bolsas e transferência de recursos humanos, na comparação dos coeficientes, se apresentam como as remunerações que são realizadas a menores distâncias. No caso dos relacionamentos que envolvem bolsas de pesquisa bem como a transferência física de recursos humanos entre as partes, isso é explicado pela necessidade de interações mais frequentes e presenciais entre os agentes. Ademais, uma das formas de reduzir a incerteza de remunerações que envolvem somente risco é através de frequentes interações (Powell; Grodal, 2005), que são propiciadas pela proximidade geográfica. 


\section{Conclusões}

Considerando os dados do Censo 2008 do DGP e controlando para informações relativas a aspectos econômicos, urbanos e locacionais dos municípios nos quais esses agentes estão cadastrados, foi possível estabelecer modelos econométricos que relacionassem as características dos grupos de pesquisa, dos relacionamentos dos grupos com empresas e da sua localização municipal com vistas a verificar, para o caso brasileiro, os principais aspectos destacados em trabalhos da área sobre os determinantes da distância na interação universidade-empresa.

Os resultados apontam congruência dos determinantes da distância das interações no Brasil com demais trabalhos nacionais e internacionais. A excelência e escala científica dos grupos de pesquisa demonstram ser positivamente correlacionadas à distância da interação que esses grupos estabelecem com empresas. Ainda, a escala econômica, a diversificação produtiva e a aglomeração urbana também respondem como fator explicativo da distância das interações.

Especificamente em relação ao foco do estudo, o tipo de instituição no qual o grupo de pesquisa está cadastrado, a grande área científica de atuação, os tipos de relacionamentos e de remuneração estabelecidos e a classificação das firmas por conteúdo tecnológico apresentam resultados estatisticamente significativos que apontam a distinção no comportamento das interações U-E em relação à distância geográfica. Grupos de pesquisa em instituições federais (de ensino e do setor empresarial) tendem a estabelecer relacionamentos com distâncias maiores que grupos de pesquisa em instituições privadas e de instituições estaduais. Nas áreas científicas de análise, os grupos que trabalham na área de ciências agrárias também apresentam comportamento diferenciado em relação às demais áreas (com exceção das ciências biológicas), com relacionamentos médios estabelecidos a distâncias maiores.

Concernente aos tipos de relacionamento, interações que envolvem resoluções de problemas para o mercado, com relacionamentos pontuais via prestação de serviços, possuem maior dependência da localidade que interações de longo prazo, que frequentemente envolvem uma rede de relacionamento melhor consolidada, e capacitações (técnica e/ou científica) em ambas as partes. Consoante a essa conclusão, interações que são remuneradas via bolsas e transferência de recursos humanos e via contratos de 
risco também dependem mais da proximidade locacional que interações via recursos financeiros e insumos materiais, evidenciando a importância da proximidade geográfica no estabelecimento de confiança mútua em relações cooperativas (Pavitt, 1998). Para os tipos de empresas, os resultados apontam que a escala produtiva (firmas intensivas em escala), a especialidade dos ativos comercializados (fornecedores especializados) e o conteúdo tecnológico das firmas (science based firms) sinalizam a possibilidade de estabelecimento de interações a distâncias maiores.

Cabe destacar, contudo, algumas limitações do trabalho e da base de dados. O Diretório dos Grupos de Pesquisa utiliza na construção dos Censos as informações da base corrente do Currículo Lattes, que são informações fornecidas voluntariamente pelo líder do grupo de pesquisa. Trabalhos anteriores (Rapini et al., 2009) já apontavam para a subestimação das interações declaradas no Diretório. Ou seja, existem interações U-E em curso no Brasil que não são captadas por esta base de dados, mas essa base é a única disponível com atualizações periódicas. Além disso, como a informação sobre interação com o setor produtivo ainda não é considerada um critério relevante de avaliação das atividades acadêmicas dos pesquisadores, não existe incentivo para que os líderes dos grupos de pesquisa mantenham essa informação atualizada.

O papel da proximidade geográfica na interação universidade-empresa é captado pela distância euclidiana entre os municípios-sede da instituição que abriga o grupo de pesquisa e o município sede da unidade do setor, não sendo analisados os aspectos cognitivos e institucionais das interações relacionados à geração de conhecimento. Parte da dimensão do conhecimento envolvido e gerado é captada por meio dos tipos de relacionamento e do tipo de remuneração que implicitamente estariam relacionados à troca de conhecimento tácito ou codificado. Contudo, são aproximações que carecem de uma análise mais específica, não sendo possível com a referida base de dados.

O papel das empresas na dinâmica da interação universidade-empresa bem como na maior ou menor relevância da proximidade geográfica é crucial como apontado por diversos trabalhos (Beise; Stahl, 1999; Mariani, 2004). Esse papel depende fortemente de elementos internos à empresa, relacionados às rotinas e às capacitações internas. Neste sentido, o uso da taxonomia da Pavitt (1984), ao focar na dimensão setorial, descarta as características únicas de cada empresa que são consideradas como tendo 
o mesmo desempenho. Ainda que cientes dessa limitação, a referida taxonomia foi utilizada por não estarem disponíveis informações ao nível das empresas e por ser amplamente utilizada para as inferências dos padrões inovativos dos setores industriais.

Mesmo com as limitações, os resultados encontrados no trabalho apontam para uma diversidade de interações universidade-empresa que parecem depender da excelência da pesquisa acadêmica e das características internas às empresas, e dos tipos de relacionamentos e interações, acontecendo por distintos mecanismos. Isto sugere a necessidade de uma ampla variedade de instrumentos de política de C\&T que considerem as diferentes especificidades de agentes e relacionamentos heterogêneos. É necessário, antes de tudo, fomentar amplos conjuntos de competências e oportunidades de interação acessíveis a esses distintos agentes, considerando suas capacitações, necessidades e possibilidades.

\section{Referências}

ACTS, Z. J; AUDRETSCH, D.B; FELDMAN, M. P. R\&D Spillovers and Recipient Firm Size. The American Economic Review, v. 82, n. 1, p. 363-367, March, 1994.

ANTONELLI, C. The Microeconomics of Technological Systems. Oxford: Oxford University Press, 2001.

ARUNDEL, A.; GEUNA, A. Proximity and the use of public science by innovative European firms. Economics of Innovation and New Technologies, v.13, n.6, p. 559-580, 2004.

ARZA, V.;VASQUEZ, C. Interactions between public research organisations and industry in Argentina: analysis of channels and benefits for researchers and firms. 2010. Disponível em http://udesa.edu.ar/sidpa/Files/SIDPA_Arza-Vazquez_2010.pdf. Acesso em 17/02/2014.

BEISE, M.; STAHL, H. Public research and industrial innovations in Germany. Research Policy, v. 28, n. 4, p. 397-422, Abril, 1999.

BITTENCOURT, P. F.; RAPINI, M. S. Padrões de Interação Universidade-Empresa em Aglomerações Inovadoras do Setor Eletro-Metal-Mecânico. Textos de Economia, Florianópolis, v. 12, n. 1, p. 104-133, jan./jun. 2009.

BITTENCOURT, P. F.; RAPINI, M. S.; PARANHOS, J. Reflexos locacionais na interação universidade-empresa, nos setores químico e farmacêutico brasileiros. Ensaios FEE, Porto Alegre, v. 33, n. 2, p. 453-482, nov. 2012.

BRENNER, T. Industrial Districts: A Typology from an Evolutionary Perspective. Danish Research Unit for Industrial Dynamics 3, Vol I: Conference on The Learning Economy - Firms, Regions and Nation Specif Institutions, Denmark, 2001.

BRESCHI, S.; LISSONI, F. Knowledge Spillovers and Local Innovation Systems: A Critical 
Survey. Industrial and Corporate Change, v. 10, n. 4, p. 975-1005, 2001.

BROSTROM, A. Working with distant researchers - Distance and content in university-industry interaction. Research Policy, v.39, p.1311-1320, 2010.

CAMPOS, B.; RUIZ, A. U. Padrões Setoriais de Inovação na Indústria Brasileira. Revista Brasileira de Inovação, Rio de Janeiro (RJ), v.8, n.1, p. 167-210, janeiro/junho 2009.

COHEN, W. M.; NELSON, R. R.; WALSH, J. P. The influence of public research on industrial R\&D. Management Science, Hanover, v. 48, n. 1, p. 1-23, jan. 2002.

COOKE, P. Introduction: Origins of the concept. In: BRACZYK, H.; COOKE, P.; HIDERNREICH, M. (Editors). Regional Innovation Systems, p. 2-25. UCL Press, London, 1998.

D'ESTE, P.; IAMMARINO, S. The spatial profile of university-business research partnerships. Papers in Regional Science, v.89, n.2, p. 336-350, 2010.

DE FUENTES, C.; DUTRÉNIT, G. Geographic proximity and university-industry interaction: the case of Mexico. The Journal of Technology Transfer. DOI 10.1007/s10961-014-9364-9. Online Version. Published online: 15 august, 2014.

FERNANDES, A. C.; SOUZA, B. C.; SILVA, A.; SUZIGAN, W.; CHAVES, C. V.; ALBUQUERQUE, E. Academy-industry links in Brazil: evidence about channels and benefits for firms and researchers. Science and Public Policy, v.37, n.7, p. 485-498, August 2010.

GARCIA, R.; ARAÚJO, V.; MASCARINI, S.; SANTOS, E. Os efeitos da proximidade geográfica para o estímulo da interação universidade-empresa. Revista de Economia, v. 37, n. especial, p. 307-330. Editora UFPR, 2011.

GARCIA, R.; ARAÚJO, V.; MASCARINI, S.; SANTOS, E. Efeitos da Qualidade da Pesquisa Acadêmica sobre a Distância Geográfica das Interações Universidade-Empresa. Estudos Econômicos, São Paulo, v. 44, n. 1, p. 105-132, jan.-mar. 2014.

GIULIANI, E. Cluster absorptive capacity: Why do some firms forge ahead and others lag behind? European Urban and Regional Studies, v.12, n.3, p. 269-288, 2005.

HADDAD, P. R. Economia regional, teorias e métodos de análise. Technical report, Fortaleza: BNB, 1989.

HARMON, B.; ARDISHVILI, J.; CARDOZO, R.; ELDER, T.; LEUTHOLD, J.; PARSHALL, J.; RAGHIAN, M.; SMITH, D. Mapping the university technology transfer process. Journal of Business Venturing. v.12, n.6, p. 423-434, November 1997.

JAFFE, A. B. Real Effects of Academic Research. The American Economic Review, v. 79, n.5, p. 957-970, December 1989.

JAFFE, A. B.; TRAJTENBERG, M; HENDERSON, R. Geographic Localization of knowledge spillovers as evidence by patent citation. The Quartely Journal of Economics, v. 108, n. 3, p. 577-598, August 1993.

KLEVORICK, A. K.; LEVIN, R.; NELSON, R.; WINTER, S. On the sources and significance of inter-industry differences in technological opportunities. Research Policy, v. 24, n. 2, p. 185-205, March 1995.

LASTRES, H.M.M. e ALBAGLI, S. Informação e globalização na era do conhecimento. Rio de Janeiro, Campus, 1999.

LAURSEN, K.; REICHSTEIN, T.; SALTERS, A. Exploring the effect of Geographical Proximity 
and University Quality on University-Industry Collaboration in the United Kingdom. Regional Studies, v.45, n.4, p. 507-523, 2011.

LEMARIÉ, S.; MANGEMATIN, V.; TORRE, A. Is the creation and development of biotech SMEs localised? Conclusions drawn from the French case. Small Business Economics v.17, p.61-76, 2001.

LIMA, A. C. Desenvolvimento Regional e Fluxos Migratórios no Brasil: uma análise para o período 1980-2010. Tese de Doutorado em Economia do Centro de Desenvolvimento e Planejamento Regional - CEDEPLAR, Universidade Federal de Minas Gerais, Belo Horizonte, 2012.

MADDALA, G. Limited advanced and qualitative variables in econometrics. Econometric Society Monographs, 1983.

MAIA, M. G. S. F. A. Integração Universidade/Empresa como Fator De Desenvolvimento Regional: Um Estudo da Região Metropolitana de Salvador. Tese de Doutorado, Universidade de Barcelona, Barcelona, 2005.

MANSFIELD, E. Academic research and industrial innovation. Research Policy, v. 20, n. 1, p. 1-12, February 1991

MANSFIELD, E. Academic research underlying industrial innovations: sources, characteristics, and financing. Rev. Econ. Stat., v. 77, n. 1, p. 55-65, Feb. 1995.

MANSFIELD, E.; LEE, J. The modern university: contributor to industrial innovation and recipient of industrial P\&D support. Research Policy, v. 25, n. 7, p. 1047-1058, October 1996.

MARIANI, M.. What determines technological hits? Geography versus firm competencies. Research Policy, v.33, p. 1565-1582, 2004.

MCKELVEY, M.; ALM, H.; RICCABONI, M. Does co-location matter for formal knowledge collaboration in the Swedish biotechnology-pharmaceutical sector? Research Policy, v. 32, p. 483-501, 2003.

MINGOTI, S. A. Análise de dados através de métodos de estatística multivariada: uma abordagem aplicada. Belo Horizonte: UFMG, 2005.

MONJON, S.; WAELBROECK, P. Assessing spillovers from universities to firms: evidence from French firm-level data. International Journal of Industrial Organization, v.21, p. 12551270, 2003.

MORGAN, K. The exaggerated death of geography: learning, proximity and territorial innovation systems. Journal of Economic Geography, v. 4, p. 3-21, 2004.

NARIN, F.; HAMILTON, K. S.; OLIVASTRO, D. The increasing linkage between U.S. technology and public science. Research Policy, v. 26, n. 3, p. 317-330, 1997.

NELSON, R. R., WINTER, S. G. Uma teoria evolucionária da mudança econômica. Campinas: Editora Unicamp, 1982.

OINAS, P.; MALECKI, E. Spatial innovation systems. In: MALECKI, E.; OINAS, P. (Ed.). Making Connections: Technological learning and regional economic change, p. 7-33. Ashgate, Aldershot (UK), 1999.

PAVITT, K. Sectoral Patterns of Technical Change: Towards a Taxonomy and a Theory. Research Policy, v. 13, p. 343-373, 1984. 
PAVITT, K. The Social Shaping of the national science base. Research Policy, v .27, n. 8, p. 793-805, 1998.

POWELL, J. L. Least absolute deviation estimation for the censored regression model. Journal of Econometrics, v. 25, n. 3, p. 303-25, 1984.

POWELL, W. W.; GRODAL, S. Networks of Innovators. In: FAGERBERG, J.; MOWERY, D.; NELSON, R. The Oxford Handbook of Innovation. Oxford: Oxford University Press, 2005, p. 56-85.

RAPINI, M. S.; OLIVEIRA, V. P.; CALIARI, T. Como a interação universidade-empresa é remunerada no Brasil: evidências dos grupos de pesquisa do CNPq. Texto para Discussão do Cedeplar, 2014.

RAPINI, M. S.; CHAVES, C. V. ; ALBUQUERQUE, E. M.; SILVA, L.; SOUZA, S. G. A.; RIGHI, H. M. ; CRUZ, W. M. S. University industry interactions in an immature system of innovation: evidence from Minas Gerais, Brazil. Science \& Public Policy, v. 36, p. 373-386, 2009.

SANTOS, U. P. Ambiente Institucional e Inovação na Siderurgia de Minas Gerais. Dissertação de Mestrado, CEDEPLAR/UFMG, 2009.

SCHARTINGER, D.; RAMMER, C.; FISHER, M. M.; FRÖHLICH, J. Knowledge interactions between universtities and industry in Austria: sectoral patterns and determinants. Research Policy, v. 31, n. 3, p. 303-328, March 2002.

SUZIGAN, W.; ALBUQUERQUE, E. The underestimated role of universities for the Brazilian system of innovation. Revista de Economia Política, v. 31, n. 1, p. 3-30, 2011.

SUZIGAN, W.; ALBUQUERQUE, E.; CÁRIO, S. Em busca da inovação: interação universidade-empresa no Brasil. Belo Horizonte: Autêntica Editora, 2011.

TOBIN, J. Estimation of relationships for limited dependent variables. Econometrica, v.26, n.1, p. 24-36, 1958.

VARGA, A. Regional Economic Effects of University Research: A survey. Working Paper, Department for Economics Geography and Geoinformatics, University of Economics and Business Administration, Vienna, 1997.

\section{Sobre os autores}

ThiagoCaliari-thicaliari@yahoo.com.br

Instituto Tecnológico da Aeronáutica, São José dos Campos, SP.

Márcia Siqueira Rapini-msrapini@cedeplar.ufmg.br

Cedeplar/Universidade Federal de Minas Gerais, Belo Horizonte, MG.

Este trabalho é um desmembramento de trabalho anterior apresentado no XVI Seminário sobre a Economia Mineira, 2014, em Diamantina, sob o título "Um Estudo sobre os Determinantes da Distância Geográfica nas Interações Universidade-Empresa". Os autores agradecem as sugestões dos dois pareceristas anônimos, isentando-os, porém, de qualquer erro ou omissão ainda presentes no artigo.

\section{Sobre 0 artigo}

Recebido em 27 de outubro de 2014. Aprovado em 26 de janeiro de 2016. 


\section{ANEXOS}

Tabela A1 Análise fatorial - Fator_CiênciaGP

\begin{tabular}{lrrrr}
\hline Ordem & Autovalor & Porcent. explicada & Porcent. acumulada \\
\hline Fator 1 & 1,31283 & $123,23 \%$ & $123,23 \%$ \\
\hline Fator 2 & 0,14198 & $13,33 \%$ & $136,56 \%$ \\
\hline Fator 3 & $-0,14118$ & $-13,25 \%$ & $123,31 \%$ \\
\hline Fator 4 & $-0,24829$ & $-23,31 \%$ & $100,00 \%$ \\
\hline Variável & Fator 1 & Fator 2 & Uniqueness \\
\hline Artigos nacionais por doutor & 0,4975 & $-0,2039$ & 0,7109 \\
\hline Art. internacional por doutor & 0,3693 & 0,2934 & 0,7775 \\
\hline Teses por doutor & 0,7314 & 0,0724 & 0,4598 \\
\hline Dissertações por doutor & 0,6276 & $-0,0954$ & 0,597 \\
\hline
\end{tabular}

Fonte: Elaboração própria.

Número de observações: 6558.

Teste $L R: \operatorname{chi} 2(6)=4598.33$ Prob $>$ chi2 $=0.0000$.

Tabela A2 Análise fatorial - Fator_Econômico Empresa

\begin{tabular}{lrrrr}
\hline Ordem & Autovalor & Porcent. explicada & Porcent. acumulada \\
\hline Fator 1 & 0,79603 & $169,63 \%$ & $169,63 \%$ \\
\hline Fator 2 & $-0,13669$ & $-29,13 \%$ & $140,50 \%$ \\
\hline Fator 3 & $-0,19007$ & $-40,50 \%$ & $100,00 \%$ \\
\hline Variável & & Fator 1 & Uniqueness \\
\hline PIB municipal & 0,5350 & 0,7138 \\
\hline PIB per capita municipal & & 0,4782 & 0,7713 \\
\hline Escala industrial municipal & & 0,5303 & 0,7188 \\
\hline
\end{tabular}

Fonte: Elaboração própria.

Número de observações: 6558.

Teste LR: $\operatorname{chi2}(3)=1819,64$ Prob $>$ chi2 $=0.0000$. 